gion and genital organs. He first sat up after eleven days, and began to drive a team after ten weeks, and has driven for four weeks since, though not well able to. I have examined him again within a few days and find him still weak, and walking like a man with a "crick" in his back, complaining of pain and weakness in his back, pain in his testicles, and loss of sexual vigor, a weak right arm and hand, tenderness over right brachial plexus and nerves of arm and forearm, and tenderness over small of the back and glutei muscles. He also has great loss of memory.

\section{ANGIONEURO'TIC CEDEMA.}

\section{nY J. G. MUM FOIRD, M.D.}

Last autumn Dr. R. W. Lovett described three cases of acute circumscribed oedema occurring in his service at the Carney Hospital." He says, "These cases were characterized by an acute and rapid swelling of one hand and forearm, which began without known cause and reached an enormous size without being accompanied by pain, local heat or constitutional disturbance." He then goes on to mention the prominent symptoms of this affection. "Slight occasional digestive disturbances, slight fever, occasional abdominal colic and watery vomiting; and negatively, no local ipain or heat, as a rule."

'This report suggested to me a case of Dr. M. H. Richardson's, of which I had the charge while house officer at the Massachusetts General Hospital last spring. The case furnished some valuable supplementary data of the symptomatology of this rare disease.

The patient was a young man of twenty, a bleeder of the most marked type, though there was no family history of hæmophilia. Four years ago he was said to have had a severe attack of purpura, and to have had a most alarming epistaxis, which ceased only when he had become apparently exsanguined. His life was then despaired of. 'There had been numerous slighter hæmorrhages at different times during his life, always controlled with difficulty. His general health had always been good.

At the time of entering the hospital, last April, be stated that, two days before, a swelling had suddenly appeared on the right cheek, beginning in the buccal cavity near the lower molars, and that within twentyfour hours the swelling had reached the size of an orange. Little pain accompanied the swelling, but great discomfort on moving the lower jaw. There was general prostration. For twelve hours there had been practically no change except occasional slight oozing of blood into the mouth.

The patient was tall and of slight build, and there was evidently a very considerable constitutional disturbance. His temperature was $103^{\circ} \mathrm{F}$., pulse 104 and feeble, respiration eighteen and labored. On the right side of the neck and jaw was a uniform swelling about the size of a large orange, centred about one inch and one-half anterior to the angle of the jaw, non-circumscribed, pale except for a few hamorrhagic spots near its centre; not painful or tender; not hot; pitting slightly on pressure. One-half of the lower lip was swollen to half again its normal size, purple and hæmorrhagic in appearance. There was a slight serohamorrhagic oozing into the mouth from behind the

1 Boston Medical and Surgical Journal, vol, exxill, page 209. second molar tooth. The jaw was moved with diffi. culty. 'There was no cedema of the glottis, but stertor on breathing, due to dislocation of the larynx from pressure. The urine was not abnormal.

Rest in bed, cold local applications and morphia were prescribed. Preparations were made for a tracheotomy, but contrary to expectation the patient passed a good night.

Till 5 P. M. of the second day the swelling steadily increased, extending down nearly to the clavicle and running around the chin as far as the angle of the jaw on the opposite side; becoming constantly more tense and painful. Cyauosis increased greatly with very labored breathing. Immediate aspiration of the tumor was proposed at this time, but postponed from hour to hour at the urgent request of the patient and his friends.

Three hours later the tumor had perceptibly diminished in size, part of its contents of clotted and liquid blood having been discharged through a spontaneous opening into the mouth. Rapid convalescence followed. Large amounts of blood, serum and clots were constantly being discharged into the mouth. Five days later the patient went home. I saw him two weeks afterwards, when there was no sign of the tumor remaining.

'The interest in this case beyond those of Dr. Lovett lies in the history of hæmophilia and former attacks of purpura. It is in them that Osler finds one of his most important diagnostic signs, and it is to that complication that the term angioneurotic is properly applied.

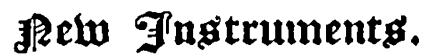

AN APPLIANCE TO FACILITATE THE INSERTION OF THE SOF'T-RUBBER (NELATON'S) STOMACH-TUBE. ${ }^{1}$

$$
\text { BY GUBTAVE LIKBMANN, M.D., }
$$

Attendtny I'hysician to I'atients with Stomach Diseases, North End Dispensary.

In the everyday use of a stomach-tube the soft elastic (Nelaton's) tube is by general agreement the one to be preferred. Although the hard-gum tubes enter the pharynx and œsophagus much more readily, they are at any rate relegated to the rarer cases of poisoning with suicidal intent, where, from obvious reasons, the application of a soft tube is not feasible. In all applications of a tube for diagnostic or therapeutic purposes we use the soft kind, as it is well-nigh impossible to do any mischief with them, and they "sit" much easier in the stomach, giving rise to less irritation or gagging than a hard tube. Still the introduction of a soft tube is at times, although generally not difficult, a source of great annoyance to both physician and patient. And why? Because for the passage of the instrument from the fauces to the beginning of the osophagus we have to depend on the intelligence and docility of the patient. He has to swallow the tube and work it through the pharynx, and only then are we enabled to push it down to the cardiac orifice. Should the patient from some cause (awkwardness, nervousness, and so on), fail to swallow, as it happens in some exceptional cases, then we are helpless and have to give up the job.

1 Read before the Section for Clinical Modloine, Pathology and Hyglede of the Massachusetts Medical Soolety, Suffolk Distriot, Jamuary 21, 1891. 
Now to overcome this difficulty I have during the last three months used $y$ simple appliance, that served me exceedingly well.

Although I designed the stylet and had it made to suit my funcy, I must state that the conception of it I got from a lady patient, returning from Professor Leube, in Wurzburg, who told me that the doctor used some sort of a staff to steady the tube. 'The stylet is made of rattan, is about thirty-four inches in length, to fit that of the ordinury Nelaton, and to project besides one and a half to two inches at the proximal end, is well smoothed down, of the thickness of a No. 6-8 English catheter (uccording to the calibre of the tube), with one end curved like the beak of a metallic bougie, but of uniform thickness from one end to the other.

MODE OF APPLICATION.

The curved end of the well-lubricated stylet is inserted and pushed forward through the tube, until it urrives at the distal end of the latter, care being taken that no part of it protrudes through any one of the openings at the end of the tube. It is advisable to bend tube and stylet still more into the requisite curve before inserting in tho fuuces. This done, the tube, with the stylet sticking out at the proximal end, is cuutiously inserted - like any other hard gum tube into the fauces and pushed forward along the pharynx to a point corresponding with the lower border of the cricoid cartilage, or in other words, to the beginning of the cosophugus, when the stylet is withdrawn, and the tube slid down to the cardiac orifice without any further trouble. You see the soft tube is changed into a stiff one but for the short minute, during which it has to pass the pharynx; we remove the stylet, and have to deal with a soft tube during the remainder of the whole procedure.

I would warn against allowing the stylet to remain within the tube below the mentioned limit, as in the first place, we don't want to use a hard tube in the cesophagus, and second, the withdrawal of the stylet underthis condition would be almost impossible. At any rate, our end in view - the overcoming of the difficulty to the passuge of the Nelaton tube - is fully reached by using the stylet only as far as the pharynx extends.

I would claim, therefore, that the stylet fulfils all the requirements of the case, dispenses with the cooperation of the patient, and that there should never be any further failure, the patient being willing and there being no organic stricture present, in introducing a soft-rubber tube into the stomach.

\section{- Reparti of Sacietieg.}

MASSACHUSETTS MEDICAL SUCIETY. SUFFOLK DISTRICT. SECTION FOR CLINICAL MEDICINE, PATHOLOGY AND HYGIENE.

ALBER' N. HLODGF'T, M.D., BECKKTARY.

Rrgular meeting, January 21, 1891. The Chairman, DR. E. G. CurLer, was detained during the tirst part of the meeting and Dr. J. J. MinOt was choosen chairmun protem.

Dr. G. Liebmann showed and debcribed an
IMPROVED APPIAANCE IOR INTRODUCTION OF THE STOM A CH-TUBE,

which commended itself to all present.

Dr. H. J. BarNes read a paper upon

SEWAGE: APPIICATION TO LAND THE BRST METHOD OF TREATMKNT. ${ }^{2}$

The Secretary read a letter from Dr. S. W. Abbot regretting his forced absence, and propounding the question, How are we to apply sewage to lund in places where no suitable land can be obtained?

\section{Discussion.}

DR. J. A. JeFrries: In pouring out so mucl drainage on the soil it might be supposed that disease would result, but practical experience shows that it does not; and so far as I know there ys no evidence that it ever does. When one considers the question closely it will be seen that this is in accordance with the ordinary laws of nature. In the first place very few of the pathogenic germs form spores in the body and the vegetative forms in passing through the drains and from exposure to sunlight are readily killed; and in these drainage farms they are put into competition with a host of other bacteria adapted to the surroundings, and following the law of the survival of the fittest they are very readily killed out. 'Those which form nitrates, etc., root and kill the others out and eat them up. These bacteria when they grow are not just like a leaf in the soil, a dry thing that forms chemical products, but; form a sticky substance, and in that way they bind the soil together and catch a great many things that otherwise would slip through. It does not seem to me.that there is any doubt that where the soil can be got that' it is the safest way of disposing of the drainage. Drainage, however, in the rivers is a constant source of danger. An instance of this was the epidemic of typhoid fever in Providence a few year's ago. And we hear of such things everywhere and at all times, In these farms we do not hear of them. I do not think there is any doubt that this is the best way of treating sewage.

Col. Glorgh E. Waring, Jr., of Newport : I have listened with very great interest to Dr. Barnes's paper. I have had the advantage of examining a large number of the towns to which he has referred as disposing of the sewage by agricultural irrigation. I have visited Gennevilliers at different times since 1875, and have kept au courant of what has been going on there, and with the very serious objections by the people and by the Council of Puris. I have seen all of those ob. jections removed and the greatest and most complete success demonstrated. My last visit was in 1889 , when about two-fifths of all the sewage of Paris, including a vast amount of water used in washing the streets, was disposed of on these lands absolutely without offence, and with such result that the effluent was not only excellent drinking.water, but was shown by chemical and biological examinations to be more pure than the best drinking-water of the city itself.

The question that seems most to interest the people of New England is, as to what shall be done with the sewage in winter. The first thought of all not familiar with the history of the work is that in a severe climute there can be no possibility of disposing of sewage in these months. I have a recent instance that is con-

See page 235 of the Journal.
See page 229 of the Jourual. 